\title{
Facile Polyolefin Plastics Hydrogenolysis Catalyzed by a Surface Electrophilic $d^{0}$ Hydride
}

\author{
Authors: Alexander H. Mason, ${ }^{1}$ Alessandro Motta, ${ }^{2}$ Anusheela Das, ${ }^{1}$ Qing Ma, ${ }^{1}$ Michael J. \\ Bedzyk, ${ }^{* 1}$ Yosi Kratish, ${ }^{* 1}$ Tobin J. Marks*1 \\ Affiliations: \\ ${ }^{1}$ Northwestern University, Evanston IL 60208, United States \\ ${ }^{2}$ Università di Roma "La Sapienza" and INSTM, UdR Roma, Piazzale Aldo Moro 5, I-00185 \\ Roma, Italy \\ *Corresponding author emails: bedzyk@northwestern.edu, yosi.kratish@,northwestern.edu, \\ t-marks@northwestern.edu
}

\begin{abstract}
Polyolefins comprise a major fraction of single-use plastics and yet their catalytic deconstruction/recycling has proven challenging due to their inert hydrocarbon connectivities. Here an electrophilic earth-abundant single-site organozirconium catalyst chemisorbed on a highly Brønsted acidic support and characterized by a broad array of experimental and theoretical techniques, is shown to mediate the rapid hydrogenolytic cleavage of molecular and macromolecular saturated hydrocarbons under mild conditions. For $n$-hexadecane, hydrogenolysis to light hydrocarbons proceeds with an activity of $690 \mathrm{~mol} n$-hexadecane $\cdot \operatorname{mol~} \mathrm{Zr}^{-1} \cdot \mathrm{h}^{-1}$ at $150^{\circ} \mathrm{C} / 2.5 \mathrm{~atm} \mathrm{H}_{2}$ pressure. Under similar solventless conditions, polyethylene, polyethylene-co1 -octene, isotactic polypropylene, and a post-consumer sandwich bag are rapidly hydrogenolyzed to low molecular mass hydrocarbons via a turnover-limiting $\mathrm{C}-\mathrm{C}$ scission pathway involving $\beta$ alkyl transfer rather than more common $\sigma$-bond metathesis.
\end{abstract}

One-Sentence Summary: "An earth-abundant organo-zirconium catalyst hydrogenolyzes diverse polyolefins with high efficiency via well-defined pathways."

Introduction. Synthetic polymers play an important role in modern society, providing critical materials for food packaging, infrastructure and transportation, clothing, medical disposables, consumer electronics, etc. In 2018, 395 million tons were produced, with 1.1 billion tons (Gt) projected annually by $2050(1,2)$. Since most plastics are single-use, global production has created a corresponding increase in derived waste and environmental impact $(3,4)$, with a cumulative 5.7 Gt of waste landfilled or incinerated to date (2). Recycling is an attractive but underutilized means of repurposing plastics, decreasing fossil fuels reliance, and addresing plastics pollution (5-7). However, today most recycling is mechanical, with polymers shredded then re-shaped into materials having inferior properties vs virgin materials (8). Among modern synthetic polymers, polyolefins comprise more than half of the production due to low cost, enormous versatility, and chemical inertness. Today polyolefins such as polyethylene, polypropylene, and polystyrene are typically recycled pyrolytically at temperatures $>400^{\circ} \mathrm{C}$. However, this energy-intensive unselective "cracking" yields hydrocarbon mixtures and significant residual "coke" (9).

Catalytic polyolefin deconstruction to lighter hydrocarbons has proven challenging due to their chemical/thermal inertness. One homogeneous approach uses an Ir catalyst and metathesis with an alkane to lower the polyolefin molecular mass (10). Polyolefins have also been hydrogenolytically upcycled over heterogeneous precious-metal $\mathrm{Pd}, \mathrm{Pt}$, $\mathrm{Ru}$ or Re catalysts to waxrange and lighter hydrocarbons. Such processes typically employ high temperatures/pressures with high catalyst loadings and long reaction times (11-17). 
Regarding earth-abundant metal polyolefin hydrogenolysis catalysts, the only example to our knowledge employed a neutral $\mathrm{d}^{0} \mathrm{Zr}$ alkyl bound to silica-alumina, which mediates relatively slow hydrogenolysis (Fig. 1A) (18). We envisioned that protonolytic chemisorption of $\mathrm{Zr}$ alkyls on highly Brønsted acidic surfaces (having weak/weakly coordinating conjugate Brønsted bases) might yield $\mathrm{d}^{0}$ catalysts sufficiently electrophilic to efficiently cleave polyolefin $\mathrm{C}-\mathrm{C}$ bonds. Note that chemisorbing $\mathrm{Cp} * \mathrm{Zr}\left(\mathrm{CH}_{3}\right)_{3}\left(\mathrm{Cp}^{*}=\eta^{5}-\mathrm{Me}_{5} \mathrm{C}_{5}\right)$ on Brønsted acidic sulfated metal oxides yields methane + electrostatically-bound cationic adsorbates (Fig. 1B) which catalyze rapid arene hydrogenation and olefin polymerization (19-21). Such catalysts operate via mechanisms differing substantially from later transition metals, raising the intriguing question of whether they might rapidly activate/hydrogenolyze polyolefins through unconventional pathways.
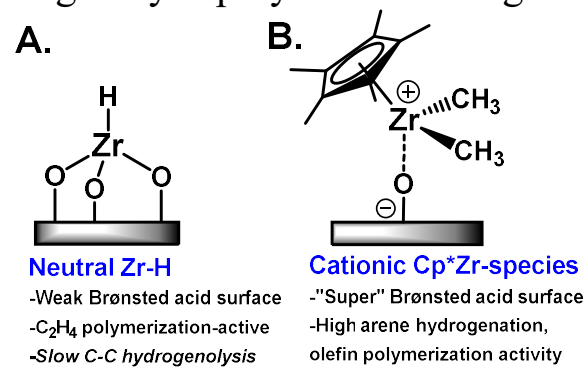

C.
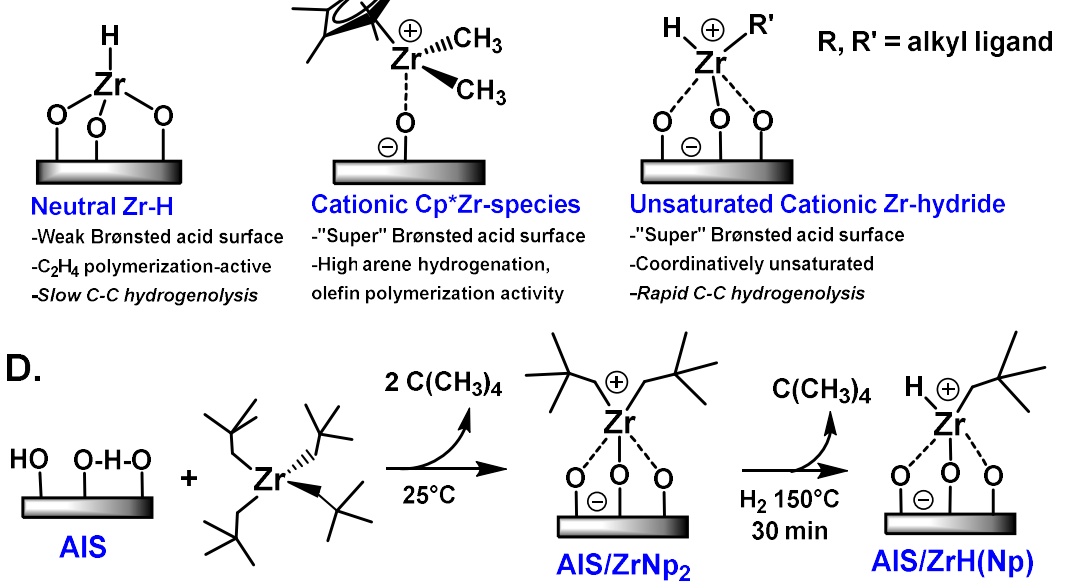

Fig. 1. Zirconium alkyl chemistry on oxide surfaces. (A) Zr hydrocarbyl-derived adsorbate on a weak Brønsted acid surface, $(\mathbf{B}) \mathrm{Cp} * \mathrm{Zr}\left(\mathrm{CH}_{3}\right)_{3}$-derived adsorbate on a "super" Brønsted acidic surface functioning as a weak conjugate base, (C) Analogous $\operatorname{Zr}$ (neopentyl) 4 -derived adsorbate after $\mathrm{H}_{2}$ exposure, (D) $\mathrm{Zr}$ (neopentyl) ${ }_{4}$ chemisorption on very Brønsted acidic sulfated alumina (AIS), and hydride generation via Zr-neopentyl hydrogenolysis.

Here we report that $\mathrm{Zr}$ (neopentyl) ${ }_{4}$ chemisorption on sulfated alumina (Hammett acidity, $\mathrm{H}_{0}$ = -14.6) (22) yields AIS/ZrNp2 (Fig. 1D), characterized by solid-state Nuclear Magnetic Resonance (NMR) and Diffuse Reflectance Infrared Fourier Transform Spectroscopy (DRIFTS), Inductively Coupled Plasma Atomic Emission Spectroscopy (ICP-AES), (X-ray Absorption Near Edge Structure (XANES), Extended X-ray Absorption Fine Structure (EXAFS), and DensityFunctional Theory (DFT) computation. AIS/ZrNp2 catalyzes the rapid, solventless hydrogenolysis of polyethylene (PE), isotactic polypropylene (i-PP), polyethylene-co-1-octene (PECO) copolymer, and consumer PE under very mild conditions. Using hexadecane (C16) as a PE model, the mechanism is first probed before proceeding to polyolefins, and $\mathbf{C 1 6}$ hydrogenolysis activities

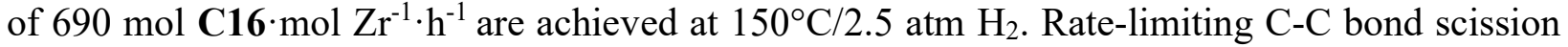
via $\beta$-alkyl transfer rather than $\sigma$-bond metathesis (common in $\mathrm{d}^{0}$ metal catalysis) $(23,24)$ predominates, in accord with DFT computation.

Catalyst Synthesis and Characterization (Details in Supplementary Materials).

AIS/ZrNp2 with a $\mathrm{Zr}$ loading of $1.40 \mathrm{wt} \%\left(\sim 0.5 \mathrm{Zr} / \mathrm{nm}^{2}\right)$ was prepared by rigorously anaerobic $\mathrm{Zr}$ (neopentyl) 4 chemisorption on AIS. Solid-state ${ }^{1} \mathrm{H}$ magic angle spinning (MAS) NMR spectroscopy reveals a $\delta 0.90$ ppm signal assignable to $\mathrm{Zr}-\mathrm{Np} \mathrm{CH}_{3}$ and $\mathrm{CH}_{2}$ moieties (Fig. 2A). Upon $\mathrm{H}_{2}$ exposure at $150^{\circ} \mathrm{C} / 30 \mathrm{~min}$, one or more neopentyl ligands are hydrogenolyzed, yielding the Zr-hydride, AIS/ZrH(Np) (Figs. 1D, 2A) with a characteristic $\delta 11$ ppm ${ }^{1} \mathrm{H} Z$ r-H NMR signal 
(25-27), not present in $\mathrm{D}_{2}$ reactions (Fig. S4). Besides weakened C-H alkyl signals, resonances at $\delta 2.0$ and $\delta 7.5 \mathrm{ppm}$ are also visible and tentatively assigned to $\mathrm{Al}-\mathrm{OH}$ and $\mathrm{Al}-\mathrm{H}$ groups, respectively $(28,29)$. DRIFTS spectra reveal $v \mathrm{Zr}-\mathrm{H}$ and $v \mathrm{Al}-\mathrm{H}$ stretching modes at $1620 \mathrm{~cm}^{-1}$ and $1930 \mathrm{~cm}^{-1}$, respectively (Fig. 2B) $(18,25)$ not present in AIS nor AIS/ZrNp2 (Fig. 2B). Furthermore, exposing $\mathbf{A l S} / \mathbf{Z r N p}_{2}$ to $\mathrm{D}_{2}$ significantly weakens these features, supporting the $\mathrm{vZr}-\mathrm{H}$ and $\mathrm{vAl}-\mathrm{H}$ assignments (Fig. S5). Additionally, the AIS/ZrNp2 3000-2800 $\mathrm{cm}^{-1}$ alkyl vC-H modes weaken upon $\mathrm{H}_{2}$ exposure, supporting $\mathrm{Zr}$-neopentyl $\rightarrow \mathbf{A I S} / \mathbf{Z r H}(\mathbf{N p})$ conversion (Fig. 2B). On exposing AIS/ZrH(Np) to pentane vapor, the Zr-H $\delta 11 \mathrm{ppm} \mathrm{NMR} \mathrm{signal} \mathrm{and} \mathrm{the} 1620 \mathrm{~cm}^{-1}$ vibration vanish, however the signals at $\delta 7.5 \mathrm{ppm}$ and $1930 \mathrm{~cm}^{-1}$ remain (Fig. S6), arguing the latter represent less reactive Al-H species.

Zr EXAFS and DFT computation provide additional chemical and electronic structural information. The former indicates that $\mathbf{A I S / Z r N p}$ is an oxide-bound $\mathrm{ZrNp}_{2}$ species having three rather long Zr-O bonds ( $2.26 \AA$ average) and two $\mathrm{Zr}-\mathrm{C}$ bonds (Figs. 2C, 2D; Table 1, entry 1) DFT-derived model for AIS/ZrNp2 (Fig. 2C), reveals three 2.18-2.24 $\AA$ Zr-O bonds, in excellent agreement with the EXAFS (Table 1, entry 1). Operando EXAFS monitoring of AlS/ZrNp2 hydrogenolysis reveals gradual conversion to $\mathbf{A l S} / \mathbf{Z r H}(\mathbf{N p})$ with the $\mathrm{Zr}-\mathrm{C}$ bond number falling from $2.0\left(\mathbf{A I S} / \mathbf{Z r N p} \mathbf{p}_{2}\right)$ to $1.0(\mathbf{A I S} / \mathbf{Z r H}(\mathbf{N p}))$ and a slight $\mathrm{Zr}$-O average bond length contraction to $\sim 2.19 \AA$ (Figs. 2C, 2D; Table 1, entry 2), consistent with the less encumbered hydride ligand replacing $\mathrm{Np}$. Further $\mathrm{H}_{2}$ treatment at $150^{\circ} \mathrm{C}$ effects minimal change, demonstrating that AIS/ZrH(Np) is stable under catalytic conditions (vide infra). From the DFT analysis, the three AIS/ZrH(Np) Zr-O bonds are slightly contracted to 2.10-2.20 $\AA$, in accord with the EXAFS data. Additionally, the DFT-computed $1704 \mathrm{~cm}^{-1} \mathbf{A I S} / \mathbf{Z r H}(\mathbf{N p}) v \mathrm{Zr}-\mathrm{H}$ frequency compares favorably with the $1620 \mathrm{~cm}^{-1}$ DRIFTS value, further supporting the structure in Figure 2C (Table 1, entry 2). $\mathbf{A I S} / \mathbf{Z r H}(\mathbf{N p})$ pentane exposure affords a $\mathbf{A I S} / \mathbf{Z r}(\mathbf{a l k y l}) 2$ species having three $\mathrm{Zr}$-O bonds and two Zr-C bonds (EXAFS), in agreement with the NMR and DRIFTS data (Fig. 2D).

Note that the AIS/ZrNp2 and $\mathbf{A I S} / \mathbf{Z r H}(\mathbf{N p}) \mathrm{Zr}$-O bonds are significantly elongated vs those in neutrally charged $2,6-{ }^{\mathrm{t}} \mathrm{Bu}_{2} \mathrm{PhOZr}(\text { benzyl })_{3}(\mathrm{Zr}-\mathrm{O}=1.94 \AA)(30)$ and $(\mathrm{L}(\mathrm{Me}) \mathrm{AlO})_{2} \mathrm{Zr}(\text { benzyl })_{2}(\mathrm{~L}$ $\left.=\left(2,6-\mathrm{Pr}_{2} \mathrm{C}_{6} \mathrm{H}_{3} \mathrm{NC}(\mathrm{Me})\right)_{2} \mathrm{CH}\right)(\mathrm{Zr}-\mathrm{O}=1.91 \AA$; Fig. 2C, Table 1, entries 3, 4) (31), and formally

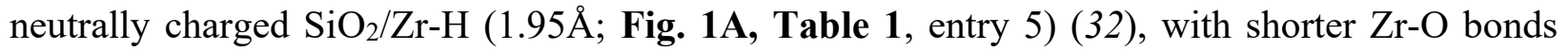
30 suggesting more covalent $\sigma$-bonding, and longer $\mathrm{Zr}-\mathrm{O}$ bonds greater electrostatic character between the electron-deficient $\mathrm{Zr}$ centers and weakly basic AIS oxide ligands $(21,33,34)$. Also, the XANES Zr K-edge energies for AIS/ZrNp2 $(18.005 \mathrm{KeV})$, AlS/ZrH(Np) $(18.008 \mathrm{KeV})$, and $\mathbf{A I S} / \mathbf{Z r}(\mathbf{a l k y l}) 2(18.006 \mathrm{KeV})$ lie in the range of cationic complexes vs neutrally charged ${ }^{t} \mathrm{Bu}_{2} \mathrm{PhOZr}(\text { benzyl })_{3}(17.998 \mathrm{KeV})$ and $\mathrm{Zr}(\text { benzyl })_{4}$ (17.999 KeV) (Fig. 2E) (20). Finally, AIS/ZrH(Np) charge partition analysis computation (35) reveals that the $\mathrm{Zr}$ atom in model $(\mathrm{EtO})_{2} \mathrm{Zr}$ (neopentyl $)_{2}$ bears a +1.66 charge vs. +1.99 in $\mathbf{A l S} / \mathbf{Z r H}(\mathbf{N p})$. Calculated $\mathrm{Zr}-\mathrm{O}$ distances are, $(\mathrm{EtO})_{2} \mathrm{Zr}(\text { neopentyl })_{2}, 1.93 \AA$, and $\mathbf{A l S} / \mathbf{Z r H}(\mathbf{N p}), 2.10-2.20 \AA$. 
A.

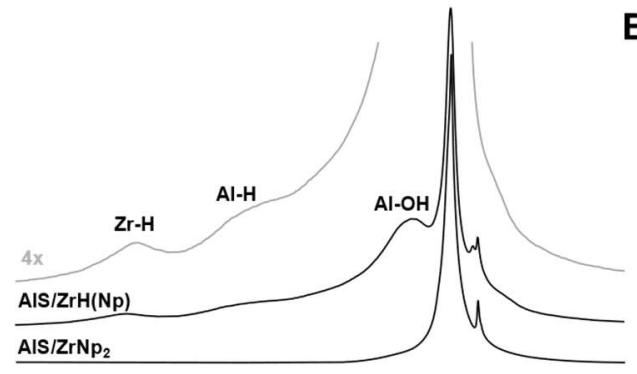

C.

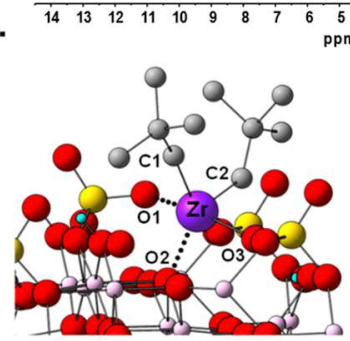

$\mathrm{AIS} / \mathrm{ZrNp}_{2}$

D.
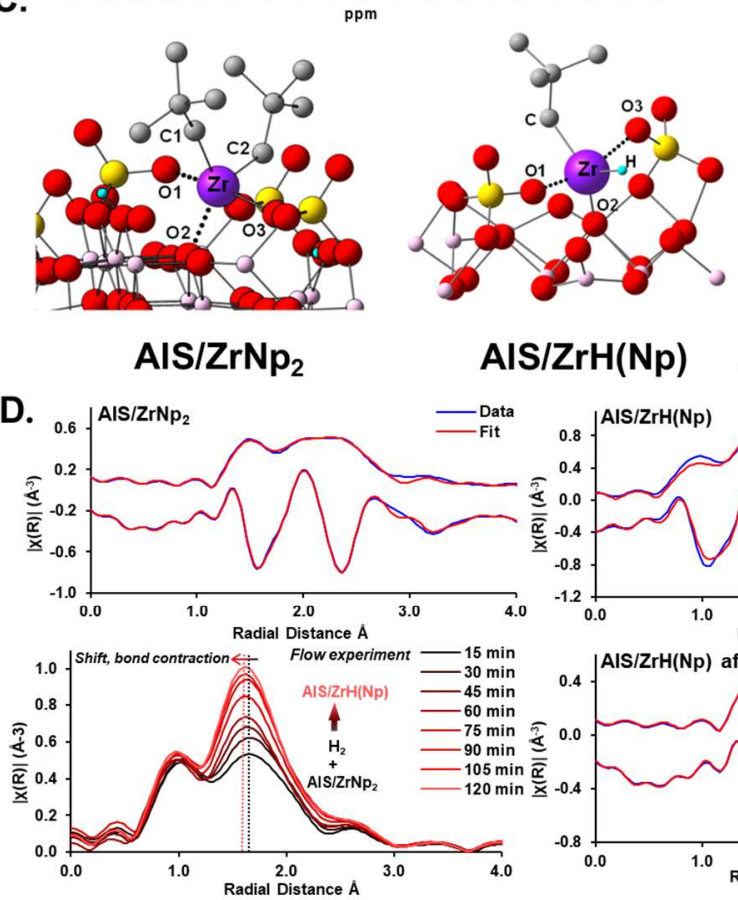

$\mathrm{AIS} / \mathrm{ZrH}(\mathrm{Np})$
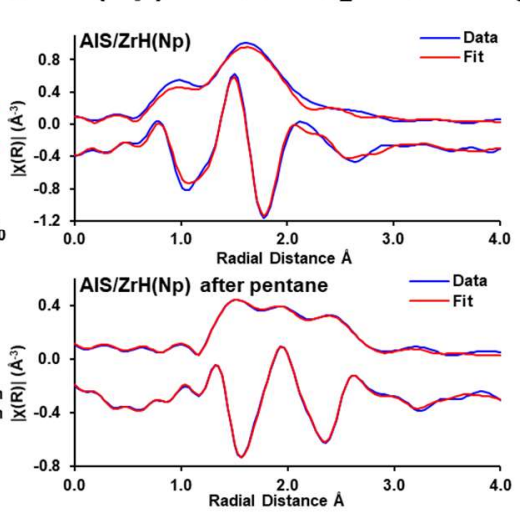
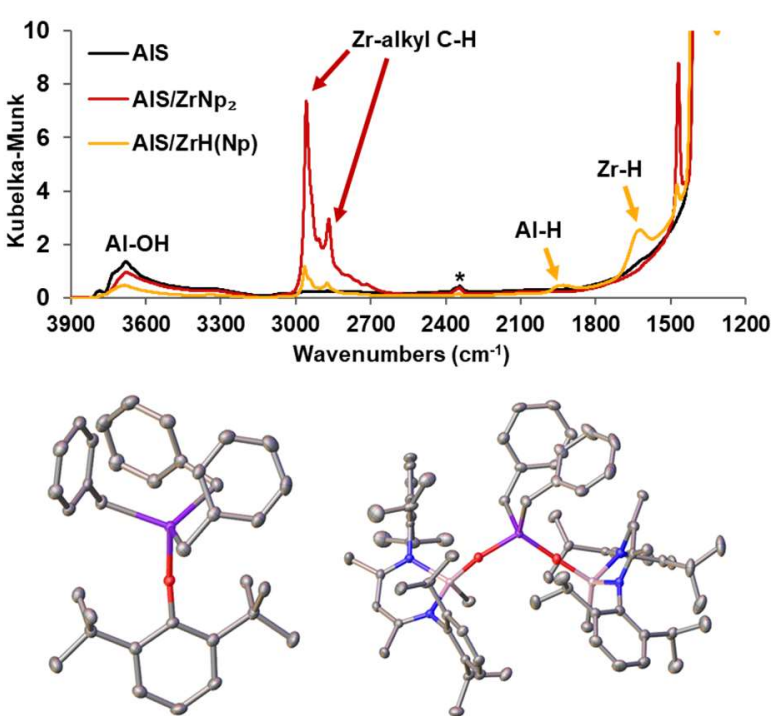

2,6-'Bu ${ }^{-} \mathrm{PhOZrBn}_{3}$

\section{(LMeAlO) ${ }_{2} \mathrm{ZrBn}_{2}$}

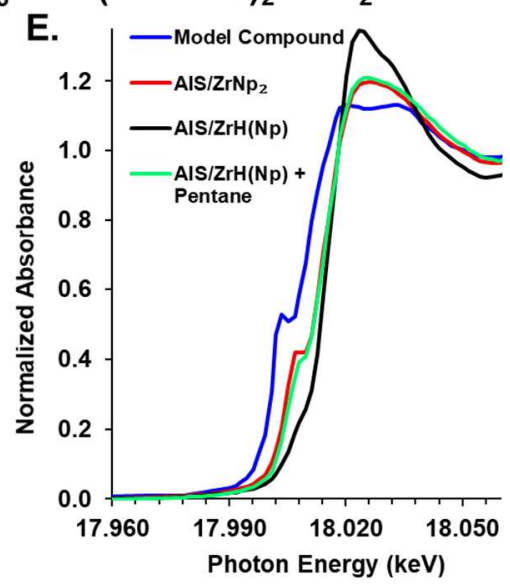

Fig. 2. Characterization of the AIS/ZrNp2 adsorbate and $\mathrm{AIS} / \mathrm{ZrH}(\mathrm{Np})$ hydrogenolysis product, and atomistic models of $\mathrm{Zr}$ dialkyl and alkyl hydride structures on AIS vs. neutrally charged model $\mathbf{Z r}$ dialkyls. (A) Solid-state ${ }^{1} \mathrm{H}$ MAS-NMR spectra of AIS/ZrNp2 and AIS/ZrH(Np); (B) DRIFTS vibrational spectra of AIS/ZrNp2, AIS/ZrH(Np), and the AIS support. * =atmospheric $\mathrm{CO}_{2}$ background artefact. (C) DFT-computed structures of AIS/ZrNيp2, AIS/ZrH(Np), and single-crystal diffraction structures of 4-coordinate Zr models. (D) EXAFS spectra of AIS/ZrNp2, AIS/ZrH(Np), and AIS/ZrH(Np) after pentane exposure (AIS/Zr(alkyl)2), and stacked operando EXAFS temporal plot for AIS/ZrNp2 hydrogenolysis at $25^{\circ} \mathrm{C}$. Real component of EXAFS spectra are offset by $-0.3 \AA^{-3}$. (E) Zr K-edge XANES of AlS/ZrH(Np), $\mathbf{A I S} / \mathbf{Z r N p} 2,\left(\mathbf{A I S} / \mathbf{Z r}\right.$ (alkyl)2), and 2,6- ${ }^{\mathrm{t}} \mathrm{Bu}_{2} \mathrm{PhOZr}(\text { benzyl })_{3}$.

Table 1. Experimental EXAFS and DRIFTS structural data for AIS/ZrNp2 and AIS/ZrH(Np), and their DFT computed metrical parameters

\begin{tabular}{|c|c|c|c|c|c|c|}
\hline Entry & Species & Bond & $\begin{array}{c}\text { Experimental } \\
\text { bond length }(\AA))^{a}\end{array}$ & $\begin{array}{l}\text { DFT bond } \\
\text { length }(\AA)\end{array}$ & $\begin{array}{l}\text { DRIFTS stretching } \\
\text { freq. } v\left(\mathrm{~cm}^{-1}\right)\end{array}$ & $\begin{array}{l}\text { DFT stretching } \\
\text { freq. } v\left(\mathrm{~cm}^{-1}\right)\end{array}$ \\
\hline \multirow[t]{4}{*}{1} & AIS/ZrNp2 & Zr-O1 & $2.26(2)$ & 2.24 & Alkyl C-H & Alkyl C-H \\
\hline & & $\mathrm{Zr}-\mathrm{O} 2$ & $2.26(2)$ & 2.20 & 2958 & 3041 \\
\hline & & $\mathrm{Zr}-\mathrm{O} 3$ & $2.26(2)$ & 2.18 & 2868 & 2679 \\
\hline & & $\mathrm{Zr}-\mathrm{C} 1$ & $2.42(3)$ & 2.12 & & \\
\hline
\end{tabular}




\begin{tabular}{|c|c|c|c|c|c|c|}
\hline & & $\mathrm{Zr}-\mathrm{C} 2$ & $2.42(3)$ & 2.22 & & \\
\hline \multirow[t]{5}{*}{2} & AlS/ZrH(Np) & $\mathrm{Zr}-\mathrm{O} 1$ & $2.29(3)$ & 2.20 & Alkyl C-H & Alkyl C-H \\
\hline & & $\mathrm{Zr}-\mathrm{O} 2$ & $2.14(3)$ & 2.10 & 2963 & 3040 \\
\hline & & $\mathrm{Zr}-\mathrm{O} 3$ & $2.14(3)$ & 2.15 & 2870 & 2966 \\
\hline & & $\mathrm{Zr}-\mathrm{C}$ & $2.38(3)$ & 2.20 & Zr-H & Zr-H \\
\hline & & $\mathrm{Zr}-\mathrm{H}$ & N.D. & 1.83 & 1620 & 1704 \\
\hline \multirow[t]{2}{*}{3} & 2,6- ${ }^{\mathrm{t}} \mathrm{Bu}_{2} \mathrm{PhOZrBn} 3$ & $\mathrm{Zr}-\mathrm{O}$ & $1.947(1)$ & N.D. & N.D. & N.D. \\
\hline & & $\mathrm{Zr}-\mathrm{C}^{\boldsymbol{b}}$ & $2.279(2)$ & & & \\
\hline \multirow[t]{4}{*}{4} & $(\mathrm{LMeAlO})_{2} \mathrm{ZrBn}_{2}$ & $\mathrm{Zr}-\mathrm{O}$ & 1.91 & N.D. & N.D. & N.D. \\
\hline & & $\mathrm{Zr}-\mathrm{O}$ & 1.91 & & & \\
\hline & & $\mathrm{Zr}-\mathrm{C}$ & 2.26 & & & \\
\hline & & $\mathrm{Zr}-\mathrm{C}$ & 2.28 & & & \\
\hline $5^{c}$ & $\mathrm{SiO}_{2} / \mathrm{ZrH}$ & $\mathrm{Zr}-\mathrm{O}^{b}$ & 1.94 & N.D. & $\begin{array}{c}\text { Zr-H } \\
1638\end{array}$ & $\begin{array}{l}\text { Zr-H } \\
\text { N.A. }\end{array}$ \\
\hline
\end{tabular}

${ }^{a}$ Entries 1, 2, and 3 from EXAFS; Entry 4 from single-crystal X-ray diffraction. ${ }^{b}$ Average of $3 \mathrm{Zr}$-O bond lengths. ${ }^{c}$ Reference (32).

Catalytic $\boldsymbol{n}$-Hexadecane and Polyolefin Hydrogenolysis (Details in Supplementary Materials). Liquid n-hexadecane $(\mathbf{C 1 6})$ (b.p. $=287^{\circ} \mathrm{C}$ ) served as a realistic PE reactivity/rheology model. Rapidly stirring (to minimize mass transport effects) $1.93 \mathrm{~mL}$ of $\mathbf{C 1 6}$ over $178 \mathrm{mg}$ of AlS/ZrNp2 $(0.05 \mathrm{~mol} \% \mathrm{Zr})$ at $150^{\circ} \mathrm{C} / 2.5 \mathrm{~atm} \mathrm{H}_{2}(350 \mathrm{~mL}$ vessel $)$ effects complete $\mathbf{C 1 6}$ conversion to $\mathrm{C} 1-\mathrm{C} 9$ hydrocarbons in as little as $18 \mathrm{~min}$ by Gas Chromatography/Mass Spectrometry (GC/MS) and Gas Chromatography/Flame Ionization Detection (GC/FID) (Table 2, entries 1-4; Video S1). Note that in all $\mathbf{C 1 6}$ hydrogenolyses, the products are linear even and odd carbon number hydrocarbons, with $\sim 1 \%$ methyl branched alkanes (Figs. S11-S13). A 24 h control with only C16 $+\mathbf{A l S}+\mathrm{H}_{2}$ yielded negligible hydrogenolysis products (Table 2, entry 5, Fig S8). Kinetic studies in which C16 conversion (at $<15 \%$ conversions) was monitored as a function of $\mathrm{H}_{2}$ pressure, catalyst loading, and time (Fig. S9) yielded the empirical rate law $v \sim \mathrm{k}[\mathrm{Zr}]^{1}\left[\mathrm{H}_{2}\right]^{0}[\mathbf{C 1 6}]^{0}$ which holds except at very low $(0.005 \mathrm{~mol} \%) \mathrm{Zr}$ loadings where trace impurity poisoning may intrude. To our knowledge, this is the first kinetic/mechanistic study of cationic $\mathrm{d}^{0}$ catalyst-mediated liquid alkane hydrogenolysis.

Table 2. C16 and polyolefin hydrogenolysis data over $\mathrm{AIS} / \mathrm{ZrH}(\mathrm{Np}) .^{a}$

\begin{tabular}{cccccccc}
\hline Entry & Substrate & $\begin{array}{c}\text { Temperature } \\
\left({ }^{\mathbf{C}} \mathbf{C}\right)\end{array}$ & $\begin{array}{c}\mathbf{H}_{\mathbf{2}} \\
\text { Pressure } \\
\mathbf{( a t m})\end{array}$ & $\begin{array}{c}\text { Reaction } \\
\text { time }(\mathbf{m i n})\end{array}$ & $\begin{array}{c}\text { Catalyst } \\
\text { loading } \\
(\mathbf{Z r ~ m o l} \mathbf{m})\end{array}$ & $\begin{array}{c}\text { Substrate } \\
\text { Conversion } \\
(\%)\end{array}$ & $\begin{array}{c}\text { Activity } \\
\left(\mathbf{h}^{-1}\right)^{\boldsymbol{b}}\end{array}$ \\
\hline $\mathbf{1}$ & $\mathbf{C 1 6}$ & 150 & 2.5 & 18 & 0.05 & $>99$ & 690 \\
$\mathbf{2}$ & $\mathbf{C 1 6}$ & 120 & 4.0 & 15 & 0.02 & 11.5 & 261 \\
$\mathbf{3}$ & $\mathbf{C 1 6}$ & 120 & 0.5 & 15 & 0.02 & 12 & 267 \\
$\mathbf{4}$ & $\mathbf{C 1 6}$ & 90 & 2.0 & 90 & 0.02 & 14.9 & 56 \\
$\mathbf{5}$ & $\mathbf{C 1 6}$ & 150 & 2.0 & 1440 & $0.00^{\boldsymbol{c}}$ & 0 & 0 \\
$\mathbf{6}$ & $\mathbf{P E}$ & 150 & 2.0 & 30 & 0.06 & $32^{\boldsymbol{d}}$ & 2088 \\
$\mathbf{7}$ & $\mathbf{P E}$ & 150 & 2.0 & 120 & 0.06 & $95^{\boldsymbol{d}}$ & 1566 \\
$\mathbf{8}$ & $\boldsymbol{i}$-PP & 190 & 2.0 & 60 & 0.12 & $96^{\boldsymbol{d}}$ & 2193 \\
$\mathbf{9}$ & $\mathbf{P E C O}$ & 190 & 2.0 & 60 & 0.07 & $>99^{\boldsymbol{d}}$ & 2995 \\
$\mathbf{1 0}$ & Sandwich bag & 190 & 2.0 & 1440 & 0.15 & $96^{\boldsymbol{d}}$ & 29
\end{tabular}

${ }^{a}$ Reaction in $350 \mathrm{~mL}$ heavy-walled glass pressure vessels. Catalyst loading with respect to $\mathrm{CH}_{2} \mathrm{CH}_{2}$ units for $\mathbf{C 1 6}$ and PE, $\mathrm{C}_{3} \mathrm{H}_{6}$ units for i-PP. ${ }^{b} \mathbf{C 1 6}$ activity: $\mathrm{mol}(\mathbf{C 1 6}) \cdot \mathrm{mol}(\mathrm{Zr})^{-1} \cdot \mathrm{h}^{-1}$; polyolefin activity: mol $\left(\mathrm{CH}_{2} \mathrm{CH}_{2}\right.$ units of $\mathrm{CH}_{2} \mathrm{Cl}_{2}$-soluble hydrocarbons + volatiles $) \cdot \operatorname{mol}(\mathrm{Zr})^{-1} \cdot \mathrm{h}^{-1}$. ${ }^{c} \mathrm{Control}$ experiment without $\mathrm{Zr}$.

${ }^{d}$ Conversion $=$ yield of combined volatiles $+\mathrm{CH}_{2} \mathrm{Cl}_{2}$-soluble hydrocarbons . 
Following the C16 experiments, linear polyethylene (PE) homopolymer, isotactic polypropylene (i-PP), polyethylene-co-1-octene (PECO), and a PE sandwich bag were investigated. The time dependence of PE hydrogenolysis with $0.06 \mathrm{~mol} \% \mathrm{Zr}$ was monitored at $150^{\circ} \mathrm{C} / 2 \mathrm{~atm} \mathrm{H}_{2}$ (Fig. 3A), with reactions halted periodically by cooling to $25^{\circ} \mathrm{C}$. Products were then extracted with $\mathrm{CH}_{2} \mathrm{Cl}_{2}$ ("DCM extract"), and the remaining partially hydrogenolyzed "solids fraction" corrected for the residual catalyst mass. A "volatile" fraction was assigned to the remaining products. While this mass could not be rigorously quantified, volatile product compositions were analyzed via headspace GC/FID. The results are shown in Figs 3B and 3C, and in Table 2, entries 6 and 7. After 2 h, 96\% of the hydrocarbon products are volatile or DCMsoluble and, as expected, have the shortest average chain lengths. The PE solids comprise only 4 $\mathrm{wt} \%$ of the product as $\leq 60$ carbon oligomers by Gel Permeation Chromatography (GPC) (Fig. S10, Table S2). Note the gradual decline in the most probable chain length of DCM extracts with conversion, falling from $\sim 18$ carbons (10 $\mathrm{min})$ to 14 carbons $(30 \mathrm{~min}), 12$ carbons $(50 \mathrm{~min})$, and 11 carbons (2h) (Fig. 3C). Minor alkane branching is detected and is ascribed to eliminated olefin reinsertion.

While linear PE homopolymer is an informative substrate due to the relatively low melting point and simple structure, i-PP and PECO are of greater technical significance (36). The AIS/ZrH(Np) catalyst was next applied to these materials at $190^{\circ} \mathrm{C}$ to lower the viscosity for ease of stirring. Reacting $1.0 \mathrm{~g}$ i-PP over $0.12 \mathrm{~mol} \% \mathbf{A I S} / \mathbf{Z r N p} 2$ under $2 \mathrm{~atm} \mathrm{H}_{2}$ effects quantitative conversion to $68 \%$ low-molecular weight $\left(\mathrm{M}_{\mathrm{w}}\right)(<\mathrm{C} 30)$ products and $28 \% \mathrm{C} 1-\mathrm{C} 6$ volatiles in only 1h (Table 2, entry 8, Figs. 3D, 3F). The i-PP DCM extract chromatogram has greater complexity than PE since the product alkanes are not only linear and have significant ethyl- and methylbranching, reflecting the PP chain cleavage point (Fig. 3E). The DCM extract number average molecular mass $\left(\mathrm{M}_{\mathrm{n}}\right)$ also falls with increasing conversion and the distribution narrows as for $\mathbf{P E}$ (Fig. 3E). Stirring PECO reaction mixtures was challenged by the viscosity. Nevertheless, hydrogenolysis proceeds rapidly to yield $85 \%$ volatile and $15 \%$ DCM soluble/low-M $\mathrm{w}_{\mathrm{w}}$ alkanes within $1 \mathrm{~h}$ (Fig. 3F). The $1 \mathrm{~h}$ and $2 \mathrm{~h}$ GC/MS data are similar, probably reflecting $\mathrm{H}_{2}$ starvation, and yielding a most probable chain length of $\sim 15$ carbons (Fig. 3G). Low-level alkane branching is present $(\sim 1 \%)$, probably from the enchained 1-octene comonomer. Finally, near complete hydrogenolysis (96\% conversion) of commercial post-consumer sandwich bags is achieved for $190^{\circ} \mathrm{C} / 2 \mathrm{~atm} \mathrm{H}_{2} / 0.15 \mathrm{~mol} \% \mathrm{Zr}$ loading in $20 \mathrm{~h}$. 

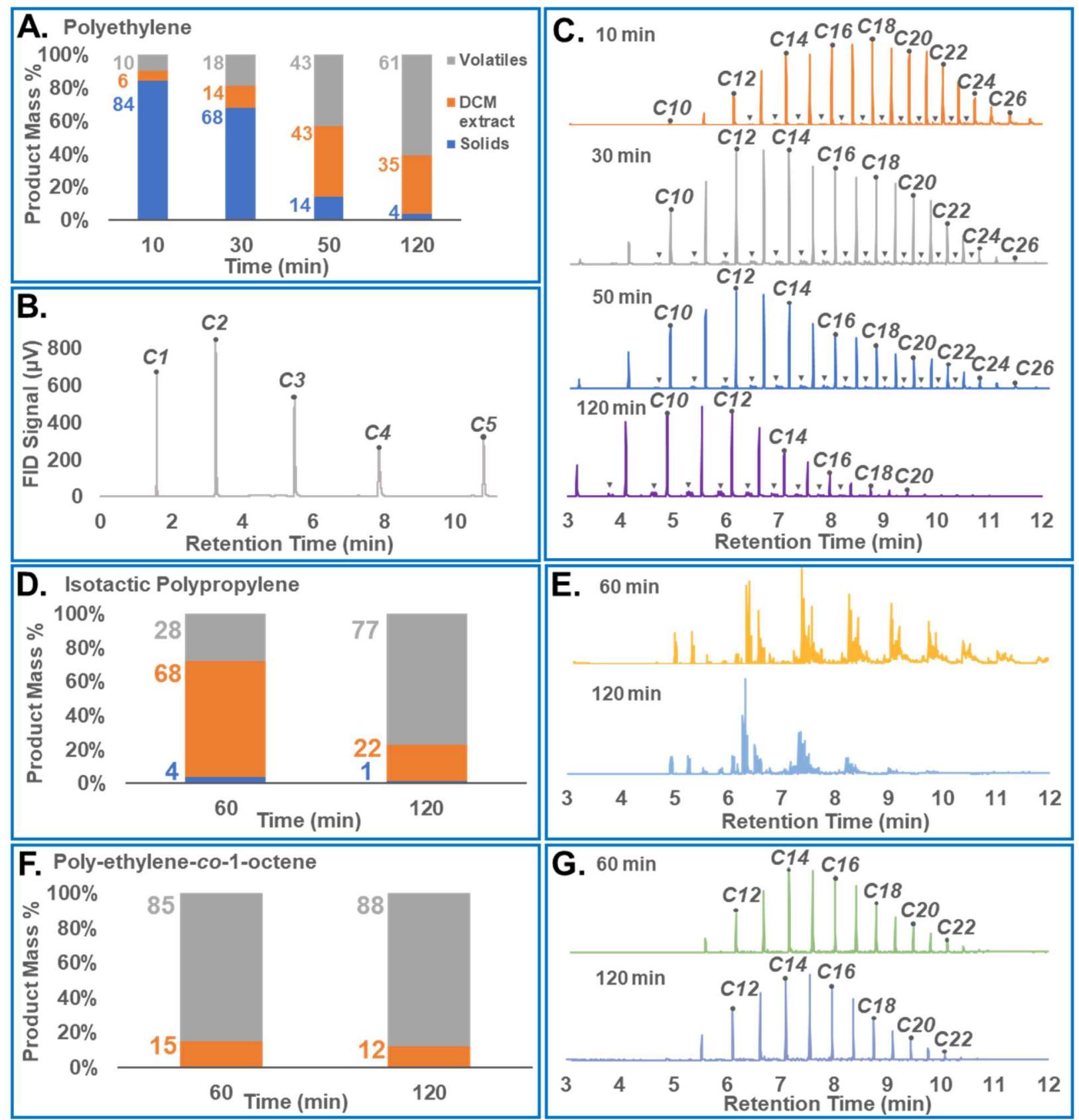

Fig. 3. Catalytic hydrogenolysis of technically relevant polyolefins. (A) Temporal product distributions for AIS/ZrNp 2 -catalyzed hydrogenolysis of linear PE $\left(150^{\circ} \mathrm{C}, 2.0 \mathrm{~atm} \mathrm{H}_{2}, 0.06 \mathrm{~mol} \% \mathrm{Zr}\right)$. (B) Headspace GC/FID chromatogram of 30 min PE hydrogenolysis. (C) GC/MS chromatograms of DCM extracts from AIS/ZrNp2-catalyzed PE hydrogenolyses. Trace chain branching denoted is by " $\boldsymbol{\nabla}$ ". (D) Temporal product distributions for the AlS/ZrNp2-catalyzed i-PP hydrogenolysis $\left(190^{\circ} \mathrm{C}, 2.0 \mathrm{~atm} \mathrm{H}_{2} 0.12 \mathrm{~mol} \% \mathrm{Zr}\right)$. (E) GC/MS chromatograms of DCM extracts from i-PP experiments. (F) Temporal product distributions for AIS/ZrNp 2 -catalyzed PECO hydrogenolysis $\left(190^{\circ} \mathrm{C}, 2.0\right.$ atm $\left.\mathrm{H}_{2}, 0.07 \mathrm{~mol} \% \mathrm{Zr}\right)$. (G) GC/MS chromatograms of DCM extracts from PECO experiments.

Reaction Mechanism (Details in Supplementary Materials).

Early transition metal $\mathrm{d}^{0}$ reaction pathways differ distinctly from most later metal systems, and frequently involve combinations of four-center $\sigma$-bond metathesis and/or $\mathrm{C}=\mathrm{C} / \mathrm{X}=\mathrm{X}$ 
insertion/extrusion. For the challenging cleavage of polyolefin $\mathrm{C}-\mathrm{C}$ bonds, as mediated by the present very unusual surface catalyst, two turnover-limiting pathways were examined: 1) $\sigma$-bond metathesis $(23,24)$ and 2) $\beta$-alkyl transfer $(37,38)$. From the present empirical rate law, $v=$ $\mathrm{k}[\mathrm{Zr}]^{1}\left[\mathrm{H}_{2}\right]^{0}[\mathbf{C 1 6}]^{0}$, with $[\mathbf{C 1 6}]$ in large excess, we infer that the turnover-limiting step or any preceding steps in rapid equilibrium, do not involve direct $\mathrm{H}_{2}$ attack at the catalytic center. From the adsorbate structures, kinetic data, control experiments, and literature precedent, DFT reaction coordinates were computed for scenarios 1) and 2) using $n$-dodecane as a model, in Figures 4A and $\mathbf{4 B}$, respectively $(19,20)$. As for catalyst choice, note that a multitude of AIS/ZrH(R) species $(\mathrm{R}=$ alkyl or $\mathrm{H})$ of similar energies are doubtless equilibrating via $\mathrm{C}-\mathrm{H} \sigma$-bond metathesis processes (Fig. 4C). AIS/Z $\mathbf{r H}_{2}$ was selected for simplicity however similar pathways are conceivable for other AIS/ZrH(R) species. For C-C scission via $\sigma$-bond metathesis (Fig. 4A), this pathway surprisingly has a prohibitive $76 \mathrm{kcal} / \mathrm{mol}$ barrier. Indeed, an experiment with ethane over a relatively high AIS/ZrH(Np) loading $(0.9 \% \mathrm{~mol} \mathrm{Zr})$, reveals negligible hydrogenolysis at $150^{\circ} \mathrm{C} / 1$ h (Eq. 1).

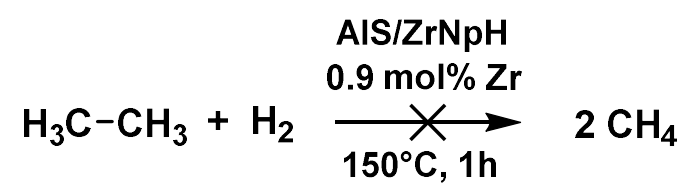

In contrast, a Zr-sec-dodecyl complex is readily accessed via $\mathrm{C}$-H $\sigma$-bond activation/metathesis of $n$-dodecane $\left(\mathrm{H}_{2}\right.$ elimination step in Fig. 4B) and is the lowest energy intermediate found on the reaction coordinate (catalyst resting state), in agreement with the experimental zero-order rate law dependence on alkane concentration. Primary or secondary $\mathrm{C}-\mathrm{H}$ activation is comparably exergonic with $\Delta \mathrm{G} \approx-5 \mathrm{kcal} / \mathrm{mol}$. Secondary activation on a polyolefin chain seems statistically more probable, with the intermediate then undergoing intramolecular $\beta$-alkyl transfer, yielding a $\mathrm{Zr}$-alkyl and olefin (Fig. 4B; $\Delta \mathrm{G}=+14.5 \mathrm{kcal} / \mathrm{mol}$ ). Here $\Delta \mathrm{G}^{\ddagger}=26.1 \mathrm{kcal} / \mathrm{mol}$ barrier and is ratelimiting for chain shortening. In principle this process is reversible, and the olefin can reinsert, explaining the $\sim 1 \%$ methyl branches in the products. The next step in this sequence is $\mathrm{Zr}$ - $\mathrm{C}$ bond hydrogenolysis with a $11.0 \mathrm{kcal} / \mathrm{mol}$ barrier to yield a $\mathrm{Zr}$ dihydride. This step is slightly endergonic $(\Delta \mathrm{G}=0.6 \mathrm{kcal} / \mathrm{mol})$ and yields shorter alkanes. Note that the barrier for Zr-C bond hydrogenolysis is slightly lower than the $\beta$-alkyl transfer step and therefore is not expected to be rate-limiting, in agreement with the experimental zero-order rate law dependence on $\mathrm{H}_{2}$ concentration. Experimentally, alkenes are not detected at any stage in the reaction, and the DFT modeling shows 30 that any alkene produced from $\beta$-alkyl transfer rapidly insert into a $\mathrm{Zr}-\mathrm{H}$ bond in a barrierless, strongly exergonic step $(\Delta \mathrm{G}=-24.2 \mathrm{kcal} / \mathrm{mol})$, and the product is then hydrogenolyzed. Therefore, overall alkane hydrogenolysis is computed to be exergonic by $\Delta \mathrm{G}=-14.3 \mathrm{kcal} / \mathrm{mol}$. While this reverse of single-site polymerization producing smaller alkenes from a longer polyalkane chain is endergonic, the coupled olefin hydrogenation renders the overall alkane, and by inference, polyethylene deconstruction, decidedly exergonic. Note that identifying AIS/ZrH(Np)-catalyzed $\beta$-alkyl transfer as the key turnover-limiting step consistent with experiment has implications for other polymers and other electrophilic transition metal catalysts. 


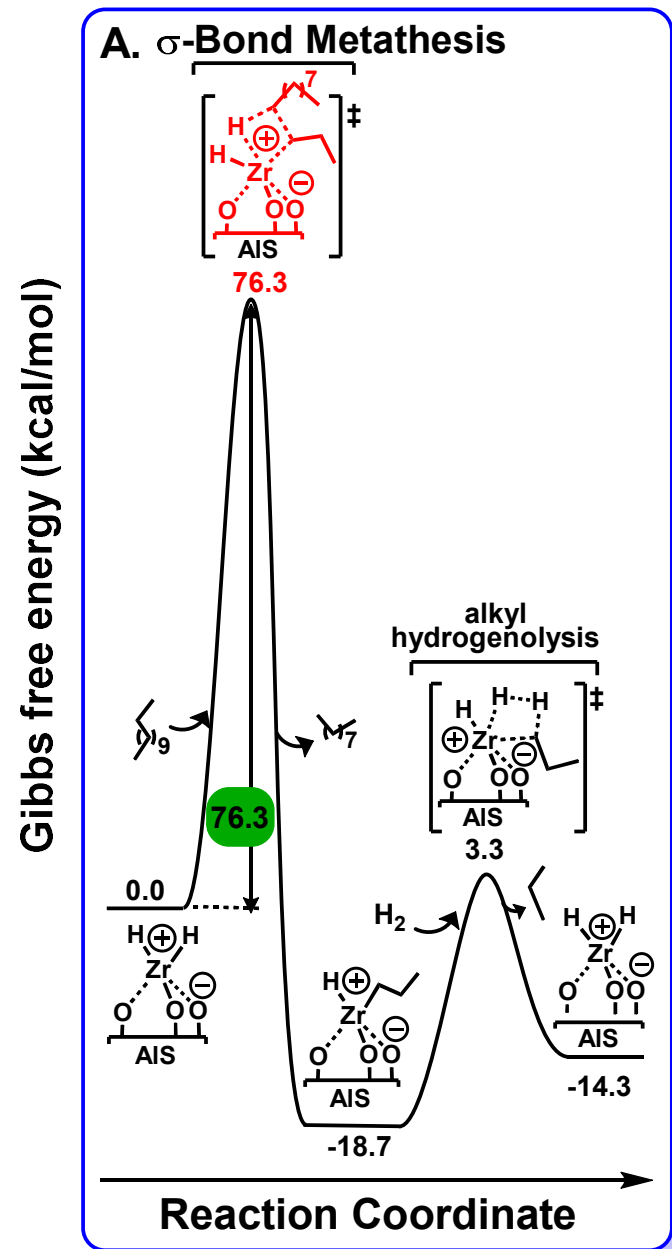

B. $\beta$-Alkyl Transfer

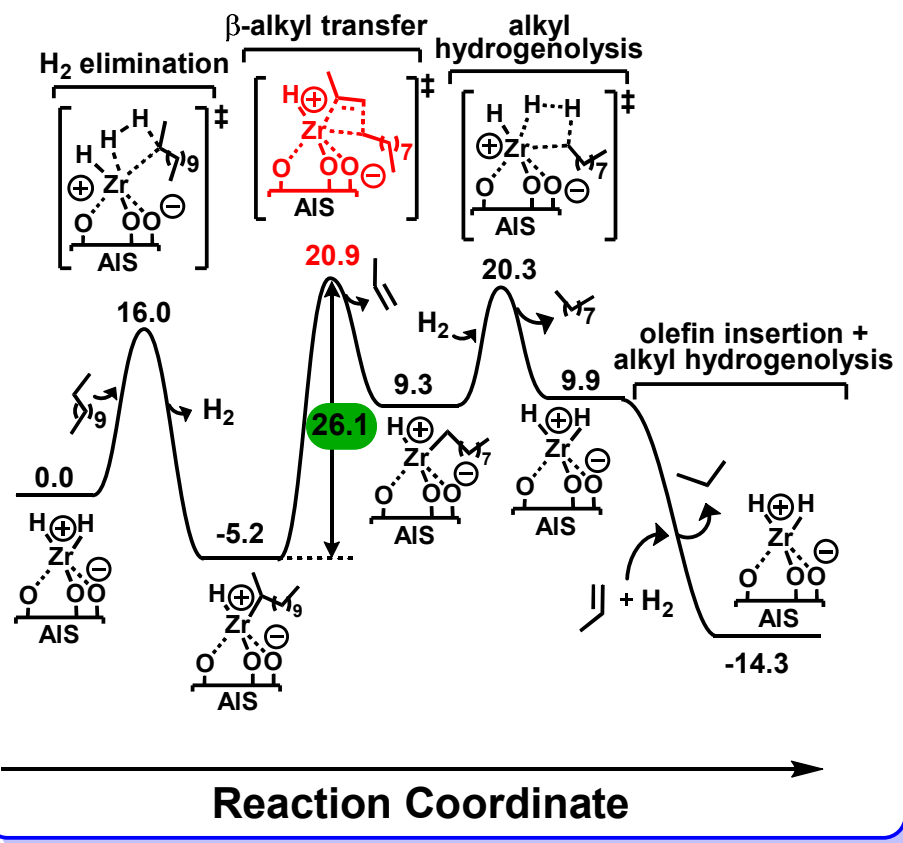

C. Hydride - Alkyl Interchange

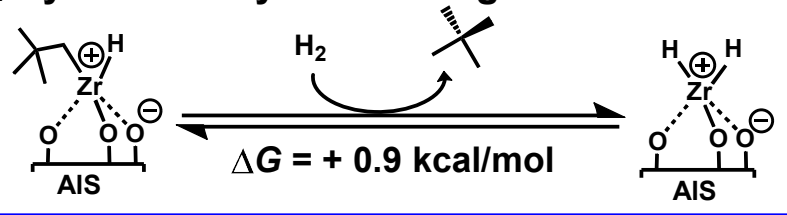

Fig. 4. Computed reaction coordinates for $\mathrm{AIS} / \mathrm{ZrH}_{2}$-catalyzed $n$-dodecane hydrogenolysis via plausible turnover-limiting pathways, (A) $\mathrm{C}$-C scission via four-center $\sigma$-bond metathesis, (B) C-C scission via intramolecular $\beta$-alkyl transfer, (C) Representative computed energetics for $\mathrm{Zr}$ alkyl/hydride ligand interchange.

\section{Conclusions}

A single-site cationic Zr-alkyl catalyst was synthesized on highly Brønsted acidic sulfated alumina and characterized by solid-state ${ }^{1} \mathrm{H}$ MAS and ${ }^{13} \mathrm{C}$ CPMAS-NMR, DRIFTS, ICP/AES, XANES, EXAFS, DFT, and evaluated for hexadecane (C16) and polyolefin hydrogenolysis. This catalyst mediates rapid $\left(690 \mathrm{~mol} \mathbf{C 1 6} \cdot \mathrm{mol} \mathrm{Zr}^{-1} \cdot \mathrm{h}^{-1}\right)$ hexadecane hydrogenolysis under relatively mild conditions $\left(150^{\circ} \mathrm{C} / 2.5 \mathrm{~atm} \mathrm{H}_{2}\right)$. Under similar solventless conditions, polyethylene, polyethyleneco-1-octene, isotactic polypropylene, and commercial $\mathrm{PE}$ are rapidly hydrogenolyzed to low molecular mass hydrocarbons under mild conditions $\left(150{ }^{\circ} \mathrm{C}-190{ }^{\circ} \mathrm{C} / 2 \mathrm{~atm} \mathrm{H}_{2}\right)$ at low catalyst loadings $(0.06 \mathrm{~mol} \% \mathrm{Zr})$. Experimental results combined with DFT computation reveal that the turnover-limiting step in alkane/polyolefin C-C scission/chain shortening is intramolecular $\beta$-alkyl transfer, in contrast to the $\sigma$-bond metathesis process common in much early transition metal catalytic chemistry. The catalytic species, a supported electrophilic Zr-hydride, is readily formed during the hydrogenolysis process. These results convey implications for deconstructing other polymers and the catalysts to achieve this. 


\section{References and Notes}

1. Ellen MacArthur Foundation (2017). The new plastics economy: rethinking the future of plastics \& catalysing action.

2. R. Geyer, J. R. Jambeck, K. L. Law, Production, use, and fate of all plastics ever made. Sci. Adv. 3, e1700782 (2017).

3. A. D. Vethaak, J. Legler, Microplastics and human health. Science 371, 672 (2021).

4. J. R. Jambeck, R. Geyer, C. Wilcox, T. R. Siegler, M. Perryman, A. Andrady, R. Narayan, K. L. Law, Plastic waste inputs from land into the ocean. Science 347, 768 (2015).

5. J. P. Lange, Towards circular carbo-chemicals - the metamorphosis of petrochemicals. Energy Environ. Sci. 14, 4358-4376 (2021).

6. J. M. Garcia, M. L. Robertson, The future of plastics recycling. Science 358, 870-872 (2017).

7. M. Hong, E. Y. X. Chen, Chemically recyclable polymers: a circular economy approach to sustainability. Green Chem. 19, 3692-3706 (2017).

8. K. Ragaert, L. Delva, K. Van Geem, Mechanical and chemical recycling of solid plastic waste. Waste Manag. 69, 24-58 (2017).

9. I. Vollmer, M. J. F. Jenks, M. C. P. Roelands, R. J. White, T. van Harmelen, P. de Wild, G. P. van der Laan, F. Meirer, J. T. F. Keurentjes, B. M. Weckhuysen, Beyond Mechanical Recycling: Giving New Life to Plastic Waste. Angew. Chem. Int. Ed. 59, 15402-15423 (2020).

10. X. Jia, C. Qin, T. Friedberger, Z. Guan, Z. Huang, Efficient and selective degradation of polyethylenes into liquid fuels and waxes under mild conditions. Sci. Adv. 2, e1501591 (2016).

11. G. Celik, R. M. Kennedy, R. A. Hackler, M. Ferrandon, A. Tennakoon, S. Patnaik, A. M. LaPointe, S. C. Ammal, A. Heyden, F. A. Perras, M. Pruski, S. L. Scott, K. R.

Poeppelmeier, A. D. Sadow, M. Delferro, Upcycling Single-Use Polyethylene into HighQuality Liquid Products. ACS Cent. Sci. 5, 1795-1803 (2019).

12. F. Zhang, M. Zeng, R. D. Yappert, J. Sun, Y. H. Lee, A. M. LaPointe, B. Peters, M. M. Abu-Omar, S. L. Scott, Polyethylene upcycling to long-chain alkylaromatics by tandem hydrogenolysis/aromatization. Science 370, 437-441 (2020).

13. J. E. Rorrer, G. T. Beckham, Y. Román-Leshkov, Conversion of Polyolefin Waste to Liquid Alkanes with Ru-Based Catalysts under Mild Conditions. JACS Au 1, 8-12 (2020).

14. P. A. Kots, S. Liu, B. C. Vance, C. Wang, J. D. Sheehan, D. G. Vlachos, Polypropylene Plastic Waste Conversion to Lubricants over $\mathrm{Ru} / \mathrm{TiO}_{2}$ Catalysts. ACS Catal. 11, 81048115 (2021).

15. C. Jia, S. Xie, W. Zhang, N. N. Intan, J. Sampath, J. Pfaendtner, H. Lin, Deconstruction of high-density polyethylene into liquid hydrocarbon fuels and lubricants by hydrogenolysis over Ru catalyst. Chem Catalysis 1, 437-455 (2021).

16. A. Tennakoon, X. Wu, A. L. Paterson, S. Patnaik, Y. Pei, A. M. LaPointe, S. C. Ammal, R. A. Hackler, A. Heyden, I. I. Slowing, G. W. Coates, M. Delferro, B. Peters, W.

Huang, A. D. Sadow, F. A. Perras, Catalytic upcycling of high-density polyethylene via a processive mechanism. Nat. Catal 3, 893-901 (2020). 
17. L. D. Ellis, S. V. Orski, G. A. Kenlaw, A. G. Norman, K. L. Beers, Y. Román-Leshkov, G. T. Beckham, Tandem Heterogeneous Catalysis for Polyethylene Depolymerization via an Olefin-Intermediate Process. ACS Sustain. Chem. Eng. 9, 623-628 (2021).

18. V. R. Dufaud, J. M. Basset, Catalytic hydrogenolysis at low temperature and pressure of polyethylene and polypropylene to diesels or lower alkanes by a zirconium hydride supported on silica-alumina: A step toward polyolefin degradation by the microscopic reverse of Ziegler-Natta polymerization. Angew. Chem. Int. Ed. 37, 806-810 (1998). From the data reported, we estimate the activity to be ca. $2 \%$ of that in Table 2 entry 6.

19. L. A. Williams, N. Guo, A. Motta, M. Delferro, I. L. Fragalà, J. T. Miller, T. J. Marks, Surface structural-chemical characterization of a single-site $\mathrm{d} 0$ heterogeneous arene hydrogenation catalyst having 100\% active sites. PNAS 110, 413 (2013).

20. W. Gu, M. M. Stalzer, C. P. Nicholas, A. Bhattacharyya, A. Motta, J. R. Gallagher, G. Zhang, J. T. Miller, T. Kobayashi, M. Pruski, M. Delferro, T. J. Marks, Benzene Selectivity in Competitive Arene Hydrogenation: Effects of Single-Site Catalyst $\cdots$ Acidic Oxide Surface Binding Geometry. J. Am. Chem. Soc. 137, 6770-6780 (2015).

21. M. M. Stalzer, M. Delferro, T. J. Marks, Supported Single-Site Organometallic Catalysts for the Synthesis of High-Performance Polyolefins. Catal. Lett. 145, 3-14 (2015).

22. K. Arata, M. Hino, Solid catalyst treated with anion: XVIII. Benzoylation of toluene with benzoyl chloride and benzoic anhydride catalysed by solid superacid of sulfate-supported alumina. Appl. Catal. 59, 197-204 (1990).

23. J. A. Labinger, J. E. Bercaw, Understanding and exploiting $\mathrm{C}-\mathrm{H}$ bond activation. Nature 417, 507-514 (2002).

24. R. Waterman, $\sigma$-Bond Metathesis: A 30-Year Retrospective. Organometallics 32, 72497263 (2013).

25. F. Rataboul, A. Baudouin, C. Thieuleux, L. Veyre, C. Coperet, J. Thivolle-Cazat, J. M. Basset, A. Lesage, L. Emsley, Molecular understanding of the formation of surface zirconium hydrides upon thermal treatment under hydrogen of [([triple bond] $\left.\mathrm{SiO}) \mathrm{Zr}(\mathrm{CH} 2 \mathrm{tBu})_{3}\right]$ by using advanced solid-state NMR techniques. J. Am. Chem. Soc. 126, 12541-12550 (2004).

26. N. Eedugurala, Z. Wang, U. Chaudhary, N. Nelson, K. Kandel, T. Kobayashi, I. I. Slowing, M. Pruski, A. D. Sadow, Mesoporous Silica-Supported AmidozirconiumCatalyzed Carbonyl Hydroboration. ACS Catal. 5, 7399-7414 (2015).

27. X. Yang, C. L. Stern, T. J. Marks, Cationic Metallocene Polymerization Catalysts. Synthesis and Properities of the First Base-Free Zirconocene Hydride. Angew. Chem. Int. Ed. Engl. 31, 1375-1377 (1992).

28. K. C. Szeto, N. Merle, J. Trébosc, M. Taoufik, R. M. Gauvin, F. Pourpoint, L. Delevoye, Caveat on the Actual Robustness of Heteronuclear NMR Methods for Probing the Surface of $\gamma$-Alumina and Related Catalysts. J. Phys. Chem. C . 123, 12919-12927 (2019).

29. B. Werghi, A. Bendjeriou-Sedjerari, A. Jedidi, E. Abou-Hamad, L. Cavallo, J.-M. Basset, Single-Site Tetracoordinated Aluminum Hydride Supported on Mesoporous Silica. From Dream to Reality! Organometallics 35, 3288-3294 (2016).

30. S. L. Latesky, A. K. McMullen, G. P. Niccolai, I. P. Rothwell, J. C. Huffman, The chemistry of sterically crowded aryl oxide ligands. 3. Crystal and molecular structure and spectroscopic properties of mixed benzyl-aryl oxide compounds of zirconium. Organometallics 4, 902-908 (1985).

31. G. B. Nikiforov, H. W. Roesky, T. Schulz, D. Stalke, M. Witt, On the quest for new mixed-metal mu-oxo-bridged complexes: synthesis of compounds containing transition 
metal-oxygen-main group metal motifs $\mathrm{M}-\mathrm{O}-\mathrm{M} 1(\mathrm{M}=\mathrm{Ti}, \mathrm{Zr} ; \mathrm{M} 1=\mathrm{Al}, \mathrm{Ga})$ without cyclopentadienyl ligands. Inorg. Chem. 47, 6435-6443 (2008).

32. J. Corker, F. Lefebvre, C. Lecuyer, V. Dufaud, F. Quignard, A. Choplin, J. Evans, J. M. Basset, Catalytic cleavage of the $\mathrm{C}-\mathrm{H}$ and $\mathrm{C}-\mathrm{C}$ bonds of alkanes by surface organometallic chemistry: An EXAFS and IR characterization of a Zr-H catalyst. Science 271, 966-969 (1996).

33. J. Zhang, A. H. Mason, A. Motta, L. G. Cesar, Y. Kratish, T. L. Lohr, J. T. Miller, Y. Gao, T. J. Marks, Surface vs Homogeneous Organo-Hafnium Catalyst Ion-Pairing and Ligand Effects on Ethylene Homo- and Copolymerizations. ACS Catal. 11, 3239-3250 (2021).

34. J. Zhang, A. H. Mason, Y. Wang, A. Motta, T. Kobayashi, M. Pruski, Y. Gao, T. J. Marks, Beyond the Active Site. Cp*ZrMe3/Sulfated Alumina-Catalyzed Olefin Polymerization Tacticity via Catalyst...Surface Ion-Pairing. Chem CatChem 13, 25642569 (2021).

35. T. A. Manz, N. G. Limas, Introducing DDEC6 atomic population analysis: part 1. Charge partitioning theory and methodology. RSC Adv. 6, 47771-47801 (2016).

36. H. P. Kiran Pulidindi, "Linear Low-Density Polyethylene (LLDPE) Market Size By Application (Films, Injection Molding, Rotomolding), Industry Analysis Report, Regional Outlook, Growth Potential, Price Trends, Competitive Market Share \& Forecast, 2016 - 2024," (2017).

37. M. E. O'Reilly, S. Dutta, A. S. Veige, $\beta$-Alkyl Elimination: Fundamental Principles and Some Applications. Chem. Rev. 116, 8105-8145 (2016).

38. X. Yang, L. Jia, T. J. Marks, Carbon-carbon activation at electrophilic d0/fn centers. Facile, regioselective .beta.-alkyl shift-based ring-opening polymerization reactions of methylenecyclobutane. J. Am. Chem. Soc. 115, 3392-3393 (1993).

39. T. D. Kühne, M. Iannuzzi, M. Del Ben, V. V. Rybkin, P. Seewald, F. Stein, T. Laino, R. Z. Khaliullin, O. Schütt, F. Schiffmann, D. Golze, J. Wilhelm, S. Chulkov, M. H. BaniHashemian, V. Weber, U. Borštnik, M. Taillefumier, A. S. Jakobovits, A. Lazzaro, H. Pabst, T. Müller, R. Schade, M. Guidon, S. Andermatt, N. Holmberg, G. K. Schenter, A. Hehn, A. Bussy, F. Belleflamme, G. Tabacchi, A. Glöß, M. Lass, I. Bethune, C. J. Mundy, C. Pless1, M. Watkins, J. VandeVondele, M. Krack, J. Hutter, CP2K: An electronic structure and molecular dynamics software package -Quickstep: Efficient and accurate electronic structure calculations. J. Chem. Phys. 152, 194103 (2020).

40. J. VandeVondele, J. Hutter, Gaussian basis sets for accurate calculations on molecular systems in gas and condensed phases. J. Chem. Phys. 127, 1-9 (2007).

41. S. Goedecker, M. Teter, J. Hutter, Separable Dual-Space Gaussian Pseudopotentials. Phys. Rev. B. 54, 1703-1710 (1996).

42. J. P. Perdew, K. Burke, M. Ernzerhof, Generalized Gradient Approximation Made Simple. Phys. Rev. Lett. 77, 3865-3868 (1996).

43. S. Grimme, J. Antony, S. Ehrlich, H. Krieg, A consistent and accurate ab initio parametrization of density functional dispersion correction (DFT-D) for the 94 elements H-Pu. J. Chem. Phys. 132, 1-19 (2010).

44. Chemcraft - graphical software for visualization of quantum chemistry computations. https://www.chemcraftprog.com. 
45. M. J. Frisch, G. W. Trucks, H. B. Schlegel, G. E. Scuseria, M. A. Robb, J. R. Cheeseman, G. Scalmani, V. Barone, G. A. Petersson, H. Nakatsuji, X. Li, M. Caricato, A. V Marenich, J. Bloino, B. G. Janesko, R. Gomperts, B. Mennucci, H. P. Hratchian, J. V Ortiz, A. F. Izmaylov, J. L. Sonnenberg, D. Williams-Young, F. Ding, F. Lipparini, F. Egidi, J. Goings, B. Peng, A. Petrone, T. Henderson, D. Ranasinghe, V. G. Zakrzewski, J. Gao, N. Rega, G. Zheng, W. Liang, M. Hada, M. Ehara, K. Toyota, R. Fukuda, J. Hasegawa, M. Ishida, T. Nakajima, Y. Honda, O. Kitao, H. Nakai, T. Vreven, K. Throssell, J. A. Montgomery Jr., J. E. Peralta, F. Ogliaro, M. J. Bearpark, J. J. Heyd, E. N. Brothers, K. N. Kudin, V. N. Staroverov, T. A. Keith, R. Kobayashi, J. Normand, K. Raghavachari, A. P. Rendell, J. C. Burant, S. S. Iyengar, J. Tomasi, M. Cossi, J. M. Millam, M. Klene, C. Adamo, R. Cammi, J. W. Ochterski, R. L. Martin, K. Morokuma, O. Farkas, J. B. Foresman, D. J. Fox, Gaussian 16 Revision B.01 (2016).

\section{Acknowledgments:}

Financial support was provided by the U.S. Department of Energy, Office of Science, Office of Basic Energy Sciences under Award Number DOE DE-FG02-03ER15457 to the Institute for Catalysis in Energy Processes (ICEP) at Northwestern University (NU). This work made use of IMSERC facilities at NU, which have received support from Soft and Hybrid Nanotechnology Experimental (SHyNE) Resource (NSF ECCS-2025633), Int. Institute of Nanotechnology (IIN), and NU. This work made use of the NU QBIC supported by NASA Ames Research Center Grant NNA04CC36G. This work made use of the REACT Facility of NU's Center for Catalysis and Surface Science supported by a grant from the DOE (DE-SC0001329). This work used the DuPont-Northwestern-Dow Collaborative Access Team (DND-CAT) 5BM-D beamline at the Advanced Photon Source (APS). DND-CAT is supported by NU, E. I. DuPont de Nemours \& Co., and The Dow Chemical Company. APS is supported by DOE at Argonne National Laboratory under Contract No. DE-AC02-06CH11357. This research was supported in part by the computational resources and staff contributions provided by the Quest High Performance Computing Facility at NU, which is jointly supported by the Office of the Provost, the Office for Research, and NU Information Technology. We thank Dr. J. Li for insightful discussions of reaction kinetics and Dr. Robert Pankow for his diligent effort in repairing, maintaining, and training students on the GPC

\section{Author contributions:}

AHM, YK, TJM conceived the ideas and designed experiments.

AHM performed most experiments with aid from YK.

AM performed the DFT analysis.

QM performed the XANES/EXAFS experiments.

AD analyzed the XANES/EXAFS data with guidance from MJB.

AHM, YK, TJM wrote the manuscript.

\section{Competing interests:}

Authors declare that they have no competing interests.

\section{Data and materials availability:}

All data are available in the main text or Supplementary Materials. 


\section{Supplementary Materials}

Materials and Methods

Supplementary Text

Figs. S1 - S16

5 Table S1-S2

References 39 - 45

Video S1 